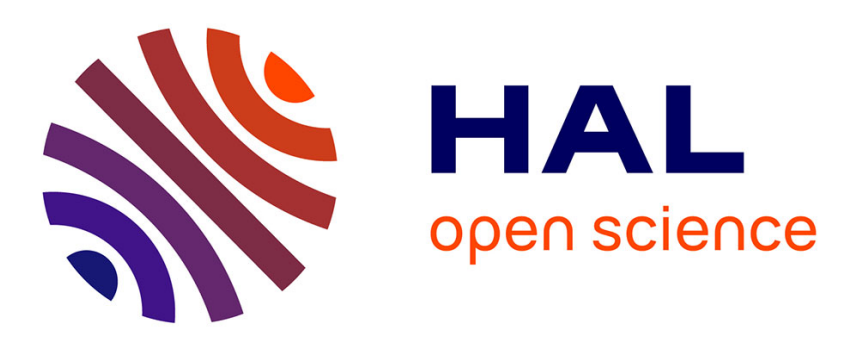

\title{
A nighttime temperature maximum in the thermosphere above Saint Santin in winter
}

\author{
W. L. Oliver, C. R. Martinis, D.A. Hickey, A.D. Wright, Christine
}

Amory-Mazaudier

\section{- To cite this version:}

W. L. Oliver, C. R. Martinis, D.A. Hickey, A.D. Wright, Christine Amory-Mazaudier. A nighttime temperature maximum in the thermosphere above Saint Santin in winter. Journal of Geophysical Research, 2012, 117, pp.1-10. 10.1029/2012JA017855 . hal-00966281

\section{HAL Id: hal-00966281 \\ https://hal.sorbonne-universite.fr/hal-00966281}

Submitted on 26 Mar 2014

HAL is a multi-disciplinary open access archive for the deposit and dissemination of scientific research documents, whether they are published or not. The documents may come from teaching and research institutions in France or abroad, or from public or private research centers.
L'archive ouverte pluridisciplinaire HAL, est destinée au dépôt et à la diffusion de documents scientifiques de niveau recherche, publiés ou non, émanant des établissements d'enseignement et de recherche français ou étrangers, des laboratoires publics ou privés. 


\title{
A nighttime temperature maximum in the thermosphere above Saint Santin in winter
}

\author{
W. L. Oliver, ${ }^{1,2}$ C. R. Martinis, ${ }^{2}$ D. A. Hickey, ${ }^{2,3}$ A. D. Wright, ${ }^{2,4}$ \\ and C. Amory-Mazaudier ${ }^{5}$
}

Received 20 April 2012; revised 21 May 2012; accepted 22 May 2012; published 29 June 2012.

[1] The Saint Santin $\left(45^{\circ} \mathrm{N}\right)$ incoherent scatter radar data base shows a local enhancement in nighttime ion temperature that occurs in winter only. Its amplitude can exceed $100 \mathrm{~K}$ and averages $40 \mathrm{~K}$ on the basis of a conservative computation. The enhancement peaks near 4 LT and has a duration of about 4 hours. We discuss two possible explanations for this feature: (1) it is caused by the convergence of global winds at the global pressure minimum, under which Saint Santin rotates at winter solstice, and (2) it is an extension or propagation of the well-known low-latitude midnight temperature maximum to midlatitudes, perhaps to that pressure minimum.

Citation: Oliver, W. L., C. R. Martinis, D. A. Hickey, A. D. Wright, and C. Amory-Mazaudier (2012), A nighttime temperature maximum in the thermosphere above Saint Santin in winter, J. Geophys. Res., 117, A06324, doi:10.1029/2012JA017855.

\section{Introduction}

[2] The Earth's thermosphere exhibits high temperature on the dayside and low temperature on the nightside. The global high temperature occurs a few hours after noon while the global low temperature occurs a few hours after midnight. Data-based models show both the high and low to occur near the equator at equinox, while at solstice the high temperature is found in the summer hemisphere and the low temperature is found in the winter hemisphere. The pressure field created by this temperature structure is balanced primarily by ion drag and consequently drives a global wind system directed from high pressure to low pressure [King and Kohl, 1965].

[3] Frequently superposed on this global structure is a low-latitude nighttime temperature maximum now known as the midnight temperature maximum (MTM), which first gained notoriety in AE-E Satellite observations [Spencer et al., 1979]. The latitudinal extent of the MTM is yet unknown. An all-sky imager used to map the ionospheric consequences of winds driven by the MTM saw a 630.0-nm "brightness wave" propagate beyond the poleward limit of

\footnotetext{
${ }^{1}$ Department of Electrical and Computer Engineering, Boston University, Boston, Massachusetts, USA.

${ }^{2}$ Center for Space Physics, Boston University, Boston, Massachusetts, USA.

${ }^{3}$ Astronomy Department, Boston University, Boston, Massachusetts, USA.

${ }^{4}$ Physics Department, Boston University, Boston, Massachusetts, USA.

${ }^{5}$ Laboratoire de Physique des Plasmas, Université Pierre et Marie Curie, Saint-Maur-des-Fossés, France.

Corresponding author: W. L. Oliver, Department of Electrical and Computer Engineering, Boston University, 8 Saint Mary's St., Boston, MA 02215, USA. (wlo@bu.edu)

C2012. American Geophysical Union. All Rights Reserved. 0148-0227/12/2012JA017855
}

its field of view at $39^{\circ}$ latitude after 3 LT [Colerico et al., 2006].

[4] Here we show evidence of a local enhancement in thermospheric temperature above Saint Santin, France $\left(45^{\circ} \mathrm{N}\right)$ in winter a few hours after midnight. We suggest two possible explanations for this enhancement: (1) it is caused by wind convergence near the global low-pressure point, under which Saint Santin rotates at winter solstice, and (2) it is an extension of the MTM, whose winds may seek this low-pressure point. Such a localized maximum superposed on the global minimum has not, to our knowledge, been identified before, nor is it found in community models of the thermosphere. We have duplicated the modeling procedure used to produce community semi-empirical models and find that, when applied to our data, the procedure fails to identify the enhancement. Adding to the model a feature characterizing the temporal behavior of the enhancement allows the feature to emerge. Below we present our data analysis that shows the effect and argue the aforementioned explanations for its cause.

\section{Data Set}

[5] Our data set is the entire ionospheric incoherent scatter radar data base for the Saint-Santin/Nançay transmitter/ receiver system $\left(45^{\circ} \mathrm{N}\right)$ as stored in the CEDAR Data Base at the National Center for Atmospheric Research (NCAR) in Boulder, Colorado, USA. These data were collected at discrete altitudes from 90 to $800 \mathrm{~km}$ in campaign style from 1966 through 1987, usually in one-day or two-day campaigns, sometimes in longer campaigns, sometimes during day or night or special periods designed to study specific atmospheric or ionospheric phenomena. Our goal is to identify any pattern of local enhancement in ion temperature $T_{i}$ at night. Figure 1 shows all 14,287 $T_{i}$ measurements collected at $350 \mathrm{~km}$ altitude with the radar during its lifetime plotted as a function of UT (LT $=\mathrm{UT}+9$ min for the radar's 


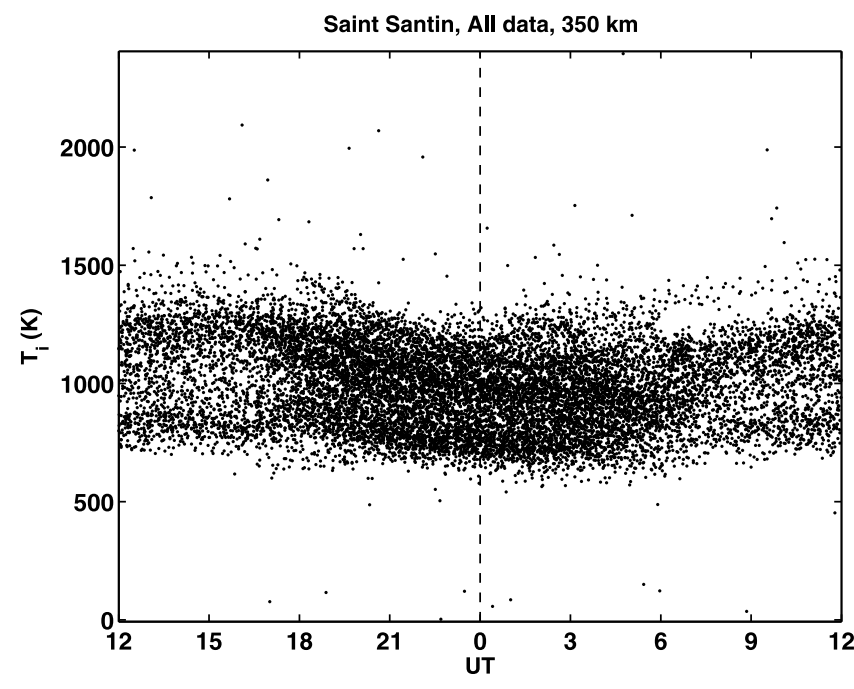

Figure 1. All Saint Santin data for $350 \mathrm{~km}$ plotted versus UT.

location). This scatterplot shows a higher concentration of data at night at $350 \mathrm{~km}$ altitude because daytime experiments shared time measuring the lower ionosphere. Bands of data show the solar-maximum and solar-minimum distribution of the data. Owing to the large scatter of the data, no nighttime temperature enhancement can be seen. The scatter has two origins, true solar-geophysical variation and measurement error. The scatter may be reduced by sorting the data into bins and averaging the data in each bin. Figure 2 shows the data so averaged into 30-minute bins. Each error bar shown is the bin standard deviation divided by the square root of the bin population and so would estimate the uncertainty in the average if the data were independent and normally distributed. This plot shows $T_{i}$ to have a smooth diurnal variation with a broad maximum from 14 to $17 \mathrm{LT}$ and a narrower minimum soon after midnight. There is no evidence here of a local maximum in temperature at night, but it is notable that the temperature does rise soon after midnight before any morning source of solar heating can occur.

[6] Figure 3 shows Figure 2 broken into four equal-length seasons centered on the solstice and equinox days. Here we start to see evidence of a local maximum in temperature on winter nights, but we see other things too that must be explained, perhaps foremost of which are the strange jumps in temperature around the times of sunrise and sunset in autumn. The reason for this behavior is that, during autumn, many daytime experiments were run during periods of lower solar activity while many nighttime experiments were run during periods of higher solar activity. With a data set so inhomogeneously collected, it is necessary, when showing data variation versus one variable, to "remove" the variations caused by the other variables. Figure 4 shows what happens to Figure 3 when the solar variation is removed by the method that we explain in the next section. The autumn variation loses its strange behavior, error bars are reduced, the winter nighttime maximum is clarified, and hints of small nighttime maxima may possibly show for spring and autumn but not for summer. It is crucial to remove the other variabilities in the data if we are to identify any local temperature enhancement at night. We now explain how we remove those other variations.

\section{Fitting the Data}

[7] We have chosen to model the entire data set, independently at each height of measurement, with a formula that accounts for variations with solar and geomagnetic activity, season, time of day, and a long-term trend. The model is discussed by Donaldson et al. [2010] but is detailed here as we will wish to add a feature to represent the nighttime temperature enhancement. Let $y$ represent year, $d$ represent day-of-year, $t$ represent hour, $\Omega=2 \pi /$ 365.2422 days, $\omega=2 \pi / 24$ hours, $F$ represent the $10.7-\mathrm{cm}$ solar flux intensity in units of $10^{-22} \mathrm{~W} / \mathrm{m}^{2}, \bar{F}$ be the threesolar-rotation average of $F, F_{\text {av }}$ be the average $F$ for our data set, $A p$ represent the daily Ap geomagnetic index, and $A p_{\text {av }}$ be the average $A p$ for our data set. The functional fit to the data is then expressed as

$$
\begin{aligned}
& \text { Fit }=\text { constant }+ \text { solar }+ \text { magnetic } \\
& + \text { seasonal }+ \text { temporal }+ \text { longterm } \\
& \text { constant }=p_{1} \\
& \text { solar }=\text { solarcycle }+ \text { solarrotation } \\
& \text { solarcycle }=p_{3}\left(\bar{F}-F_{\text {av }}\right)+p_{4}\left(\bar{F}-F_{\text {av }}\right)^{2} \\
& \text { solarrotation }=p_{5}(F-\bar{F})+p_{6}(F-\bar{F})^{2} \\
& \text { magnetic }=p_{9}\left(A p-A p_{\text {av }}\right) \\
& \text { seasonal }=\text { annual }+ \text { semiannual } \\
& \text { semiannual }=p_{10} \cos 2 \Omega d+p_{11} \sin 2 \Omega d \\
& \text { annual }=\left(p_{12} \cos \Omega d+p_{13} \sin \Omega d\right) \times\left(1+p_{7} \times \text { solar }\right) \\
& \text { temporal }=(\text { diurnal }+ \text { semidiurnal }+ \text { terdiurnal }) \\
& \times\left(1+p_{8} \times \text { solar }\right) \\
& \text { diurnal }=\left(p_{14}+p_{15} \cos \Omega d+p_{16} \sin \Omega d\right) \cos \omega t \\
& +\left(p_{17}+p_{18} \cos \Omega d+p_{19} \sin \Omega d\right) \sin \omega t \\
& \text { semidiurnal }=\left(p_{20}+p_{21} \cos \Omega d+p_{22} \sin \Omega d\right) \cos 2 \omega t \\
& +\left(p_{23}+p_{24} \cos \Omega d+p_{25} \sin \Omega d\right) \sin 2 \omega t \\
& \text { terdiurnal }=\left(p_{26}+p_{27} \cos \Omega d+p_{28} \sin \Omega d\right) \cos 3 \omega t \\
& +\left(p_{29}+p_{30} \cos \Omega d+p_{31} \sin \Omega d\right) \sin 3 \omega t
\end{aligned}
$$

It is based closely on the MSIS-model formulation [Hedin, 1987] reduced to a single geographic location. It has parabolic solar-cycle and solar-rotation variations; a linear magnetic-activity variation (a more-complicated variation was not needed for the low magnetic latitude of Saint Santin); sinusoidal annual and semi-annual variations, with the annual variation allowed a solar dependence; diurnal, semidiurnal, terdiurnal time-of-day variations, all allowed both seasonal and solar dependences; and a linear long-term trend not found in MSIS but apparent in trend analyses of the Saint Santin data [Donaldson et al., 2010; Walsh and Oliver, 2011]. The " $p$ " parameters in equation (1) are adjusted to obtain best least-squares fit to the data. We use "clipped weighting" in the fit. To data value $y_{i}$ with uncertainty $\Delta y_{i}$, we assign the weight $1 / \Delta y_{i}^{2}$ for $\Delta y_{i}>$ median $(\Delta y), 1 /$ median $(\Delta y)^{2}$ for $\Delta y_{i}<\operatorname{median}(\Delta y)$. Such weighting provides three 


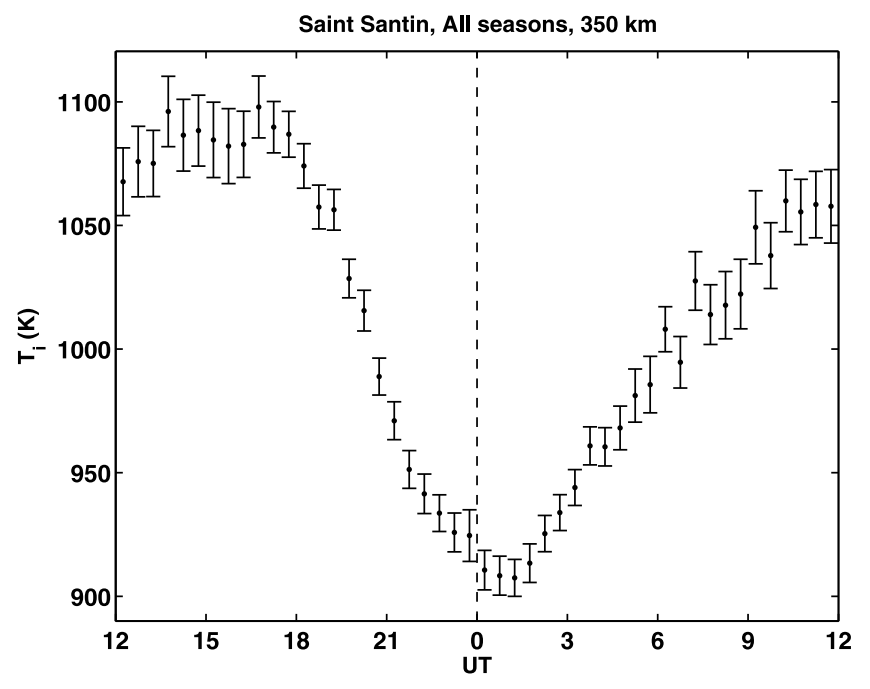

Figure 2. All Saint Santin data for $350 \mathrm{~km}$ binned versus UT.

safeguards needed with our data set: it gives little influence to poor data, it prevents excessive control of the fit by a small minority of well-determined data, and it guards against control by data with erroneously small uncertainties.

\section{Removing Variations From the Data}

[8] We can remove the solar dependence from the data by subtracting the term "solar" from the term "Fit" in equation (1), which is equivalent to setting $p_{3}, p_{4}, p_{5}$, and $p_{6}$ to zero after the full fit is made, and the result then applies for average solar conditions, $\bar{F}=F_{a v}$ and $F=\bar{F}$. The magneticactivity, seasonal, and long-term variations may similarly be removed. Instead of removing all model variations but one, it is simpler to remove all model variations then add back the variation of interest. Removing all variations gives a collection of data-minus-model residuals, which are then superposed on the variation of interest, the time-of-day variation (constant + diurnal + semidiurnal + terdiurnal) in our case. The time-of-day variations that we show in subsequent plots have all variations except the constant and diurnal harmonics removed, with residuals averaged in halfhour bins.

[9] Figure 5 shows Figure 4 with those other variations removed. Also shown is the model curve evaluated for the mean conditions of the data included in the plot (as noted on each panel). Clearly the model curve chosen (24-hour, 12hour, 8-hour periods) cannot fit the sharper post-midnight feature seen in winter. Note that the smooth curve in a panel is not a fit to the data in the panel. A single fit was made to the collected all-season data, then that fit was evaluated for the mean conditions of the data in the panel. Figure 6 shows the data broken into months instead of seasons to show more clearly when the nighttime feature occurs.

\section{The Temperature Enhancement Formulation}

[10] Because the nighttime temperature enhancement, which we will call simply the "enhancement" for brevity, is restricted to certain hours of the day and days of the year, we have added an extra term to our model (equation (1)) to represent it with gaussian windows in UT and season to restrict its appearance:

$$
p_{32} \times \exp \left[-\frac{\left(\text { hour }-p_{33}\right)^{2}}{2 p_{34}^{2}}\right] \times \exp \left[-\frac{\left(\text { day }-p_{35}\right)^{2}}{2 p_{36}^{2}}\right] .
$$

Here $p_{32}$ is the magnitude of the enhancement, which maximizes at hour $p_{33}$ on day $p_{35}$, and $p_{34}$ and $p_{36}$ are the "onesigma" half-widths of the feature in hours and days. Figure 7 shows the result of a fit of this formulation. Two solid-line curves are shown in each panel. One is the fitted curve,
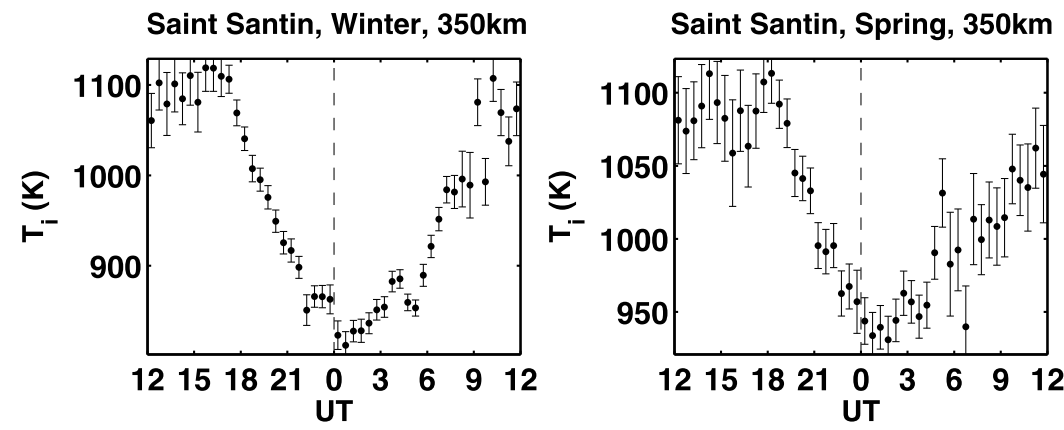

Saint Santin, Summer, 350km
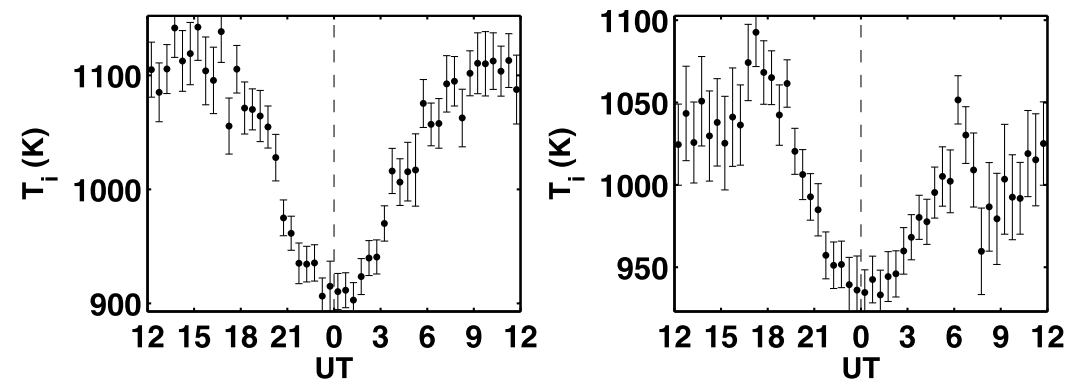

Figure 3. All Saint Santin data for $350 \mathrm{~km}$ binned versus UT and season. 

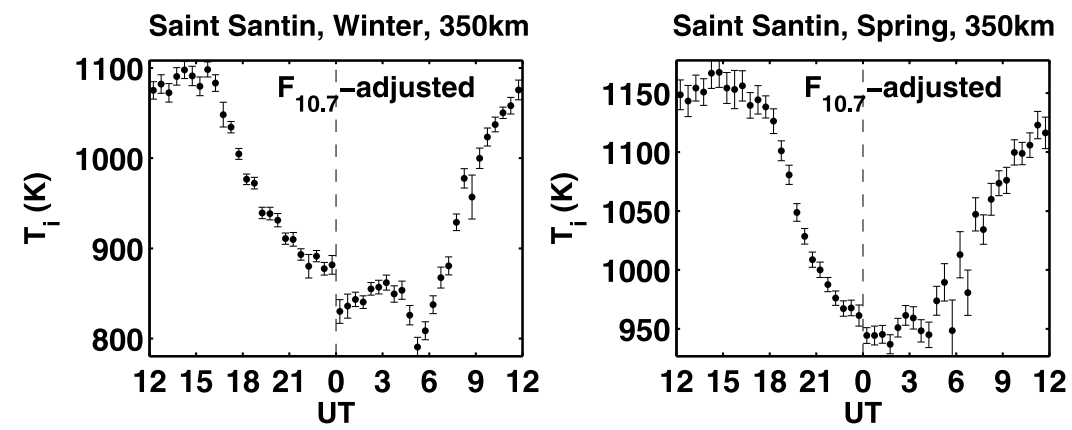

Saint Santin, Summer, 350km

Saint Santin, Autumn, 350km
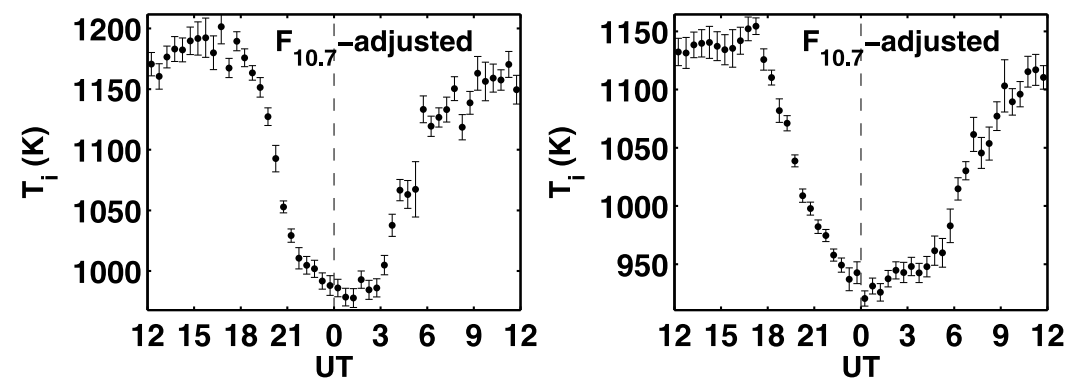

Figure 4. All Saint Santin data for $350 \mathrm{~km}$ binned versus UT and season, with solar dependence removed.

including the enhancement. It fits the data well. The other is this same curve with the enhancement subtracted $\left(p_{32}\right.$ set to zero). The second curve could be thought of as representing what the temperature of the background atmosphere would be if the process creating the post-midnight feature were not active. Note that while the enhancement produces a clear maximum in winter, it has a substantial magnitude in autumn, though it does not create a local maximum then, and an identifiable effect in spring, but no identifiable effect in summer.

[11] An alternate measure of the enhancement amplitude, peak hour, and width would come from inspection of the smooth fitted curve itself, namely, its nighttime peak and the valleys to left and right of the peak. The enhancement center hour would be the time of this peak, the enhancement width would be the difference in the times of the valleys, and the enhancement amplitude would be the difference between the

Saint Santin, Winter, 350km
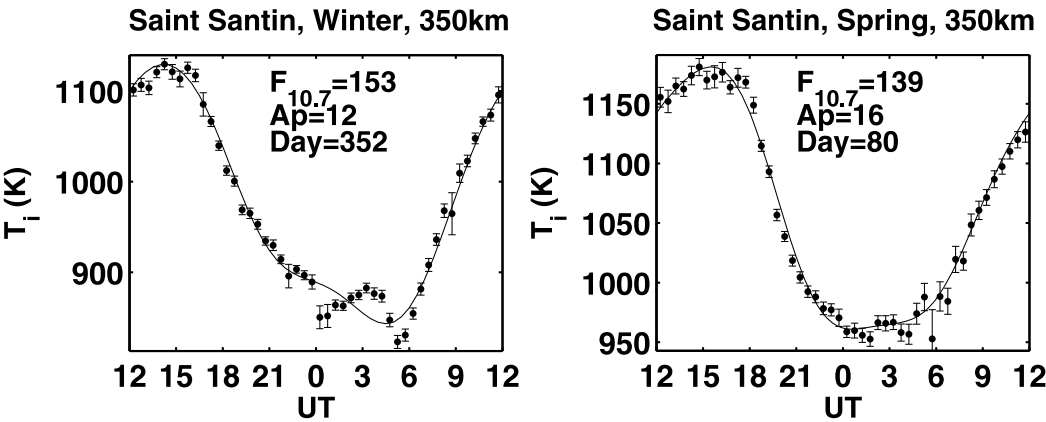

Saint Santin, Summer, 350km

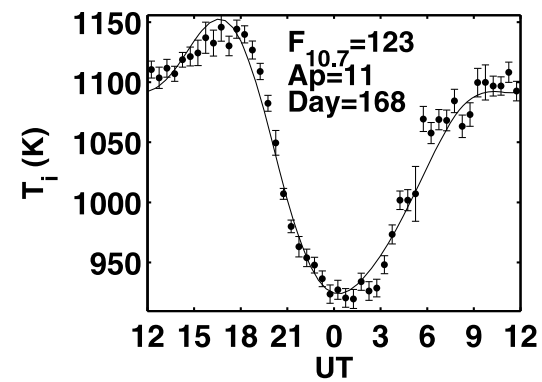

Saint Santin, Autumn, 350km

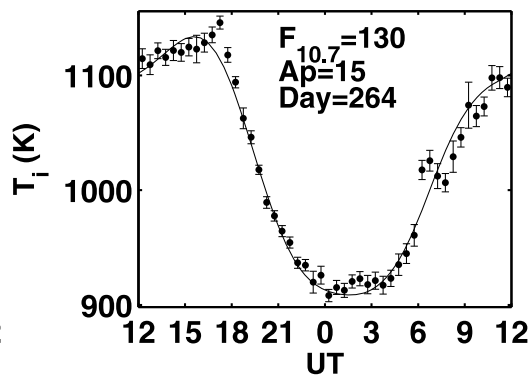

Figure 5. All Saint Santin data for $350 \mathrm{~km}$ binned versus UT and season, with solar, magnetic, seasonal, and long-term variations removed. The smooth curve is a model fit. 


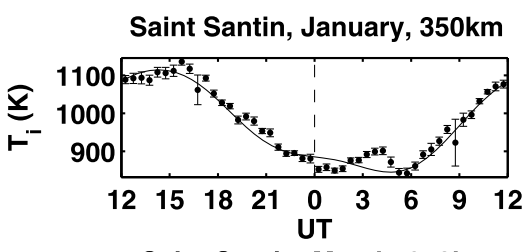

Saint Santin, March, 350km

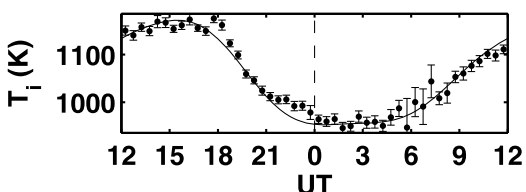

Saint Santin, May, 350km

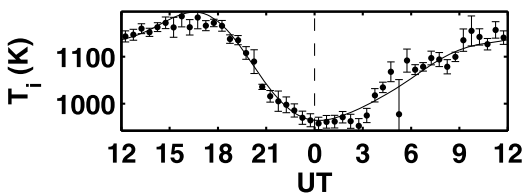

Saint Santin, July, 350km

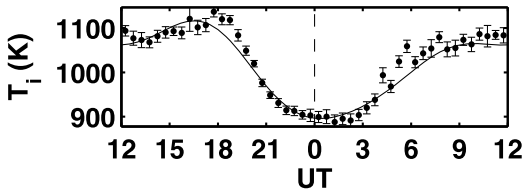

Saint Santin, September, 350km

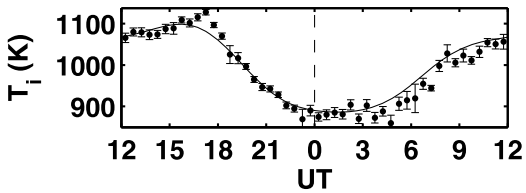

Saint Santin, November, 350km

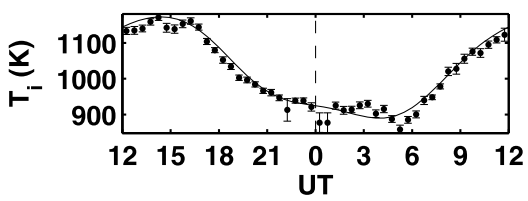

Saint Santin, February, 350km

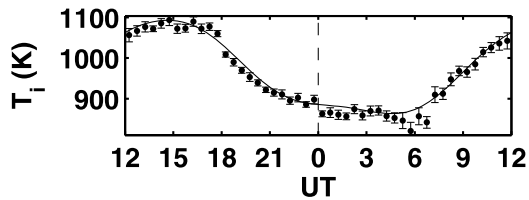

Saint Santin, April, 350km

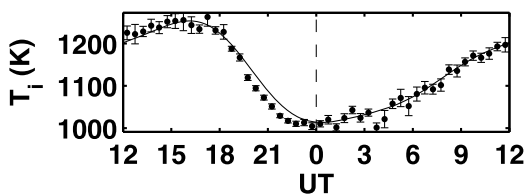

Saint Santin, June, 350km

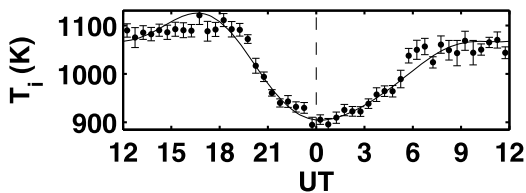

Saint Santin, August, 350km

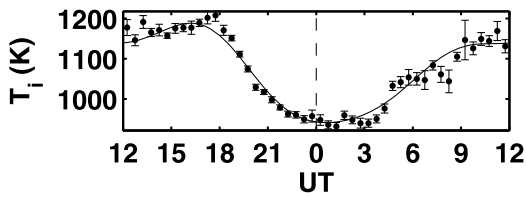

Saint Santin, October, 350km

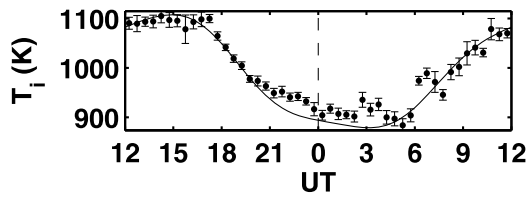

Saint Santin, December, 350km

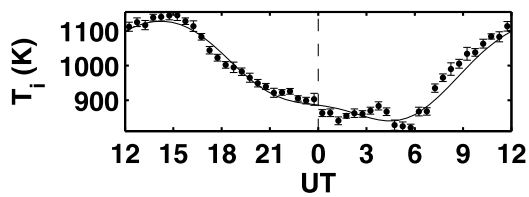

Figure 6. All Saint Santin data for $350 \mathrm{~km}$ binned versus UT and month, with solar, magnetic, seasonal, and long-term variations removed. The smooth curve is a model fit.

temperature at the peak and the average of the temperatures at the valleys, all calculated at the day of maximum enhancement effect $\left(p_{35}\right)$. The drawback to this definition is that a small heating effect, while raising the temperature, would not necessarily result in a local temperature maximum but only a degree of plateauing.

[12] To determine a possible solar-activity dependence of the enhancement, we replaced amplitude $p_{32}$ by $p_{32} \times$ $\left[1+p_{37}\left(\bar{F}_{10.7}-140\right)\right]$ in the fit. The answer was $p_{37}=(0.14 \pm 1.0) \times 10^{-3}$, indicating that the fitter had the ability to detect such a change in amplitude of only $10 \%$ or larger for a change in $\bar{F}$ of 100 but found no significant change at that level. The solar dependences of the other terms, $p_{33}-p_{36}$, were also checked and found to be undetectable. Similarly, the magnetic activity of the gaussian amplitude was checked and found to be $p_{32} \times\left[1+(1 \pm 3) \times 10^{-3} \times A p\right]$, indicating that the fitter had the ability to detect such a change in amplitude of $30 \%$ or larger for a change in Ap of 100 but found no significant change at that level. In summary, no solar-activity or magnetic-activity dependence in the nighttime temperature enhancement is detectable from the data, though we may note that though energy-per-molecule may not change with changing activity, the number of molecules does.

[13] A study of this type might normally begin by showing the supposed enhancement on individual nights and then proceed to a statistical study. We have not followed this pattern of presentation because the enhancement amplitude even at winter solstice measures only about $40 \mathrm{~K}$ peak-to-valley on average at $350 \mathrm{~km}$ altitude while the typical uncertainty in $T_{i}$ ranges from $20 \mathrm{~K}$ at midnight to $25 \mathrm{~K}$ at $4 \mathrm{LT}$. So the enhancement is often difficult to distinguish clearly on individual nights while it is clearly distinguished in the average. Nevertheless, there are a number of experiments that showed a relatively large enhancement amplitude and/or lower $T_{i}$ uncertainties, and we show a collection of those results in Figure 8. Each panel includes a model fit to the data shown. The model includes a constant, three diurnal harmonics, a linear trend, and a gaussian enhancement feature. Here we see a number of two-day or three-day sequences illustrating nights of repeated enhancement occurrences of 
Saint Santin, Winter, 350km

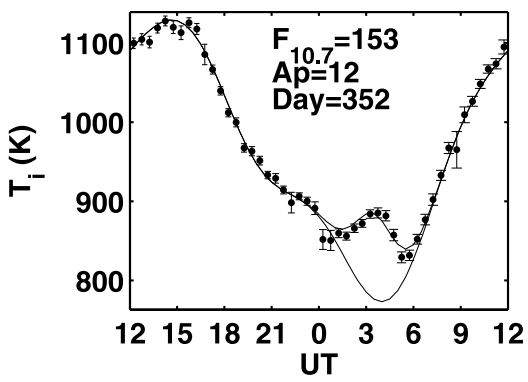

Saint Santin, Summer, 350km

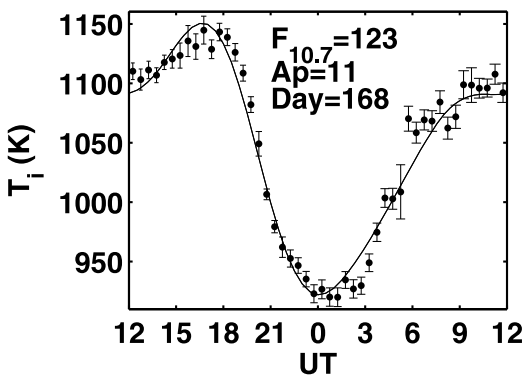

Saint Santin, Spring, 350km

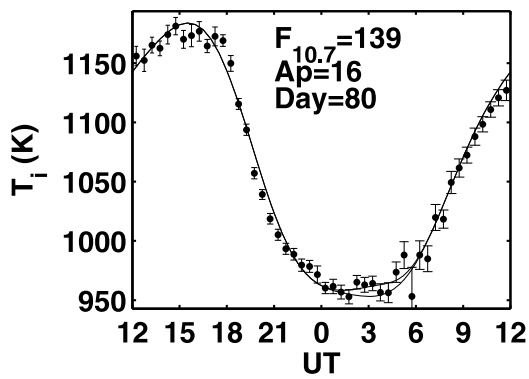

Saint Santin, Autumn, 350km

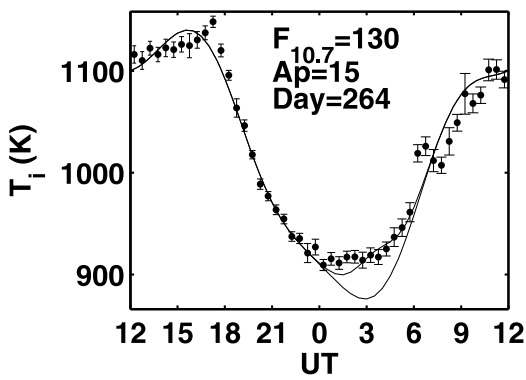

Figure 7. All Saint Santin data for $350 \mathrm{~km}$ binned versus UT and season, with solar, magnetic, seasonal, and long-term variations removed. Two model curves are shown. One is the full fit to the data, including the enhancement term. The other is the same fit with the enhancement amplitude set to zero.

large amplitude. The 1982.2.16-1982.2.17 night and the following night show a night with no significant enhancement followed by a night with a large enhancement. The 1982.6.161986.6.17 night shows another case of no significant enhancement. In reality we searched to find these "clean" examples. Most nights show more irregular behavior owing presumably to the vagaries of weather, winds, and gravity waves passing through. It is only in the average that the weather is reduced to the point at which the "permanent" nature of the enhancement is revealed. Note that the timing of the enhancement is stable around 4 UT in Figure 8, so the width of the statistical enhancement shown in prior figures may not be much broader from that on individual days.

\section{The Enhancement at Other Altitudes}

[14] We have developed our analysis using data from $350 \mathrm{~km}$ because this altitude had the greatest number of measurements. We show in Figure 9 the results obtained at all eight altitudes providing sufficient data in each half-hour bin for statistical study. Because the enhancement is largely a winter phenomenon, for brevity of presentation we show only the winter results in Figure 9. The lower "background" curve is clipped for 400 and $450 \mathrm{~km}$ altitude as they plunge to values near $500 \mathrm{~K}$ at $400 \mathrm{~km}$ and $0 \mathrm{~K}$ at $450 \mathrm{~km}$. For these altitudes large gaussian amplitudes, combined with large diurnal, semidiurnal, and terdiurnal terms all phased to oppose the gaussian, create credible fits, though those individual terms of these fits have no physical meaning. The lower solid curves in these two panels certainly do not represent how the temperature would behave in the absence of the process that caused the enhancement. Parameter $p_{32}$ may be a reliable measure of the amplitude of the enhancement only in the altitude range $250-350 \mathrm{~km}$ for which we have the largest number of data and greatest radar signal strength. We

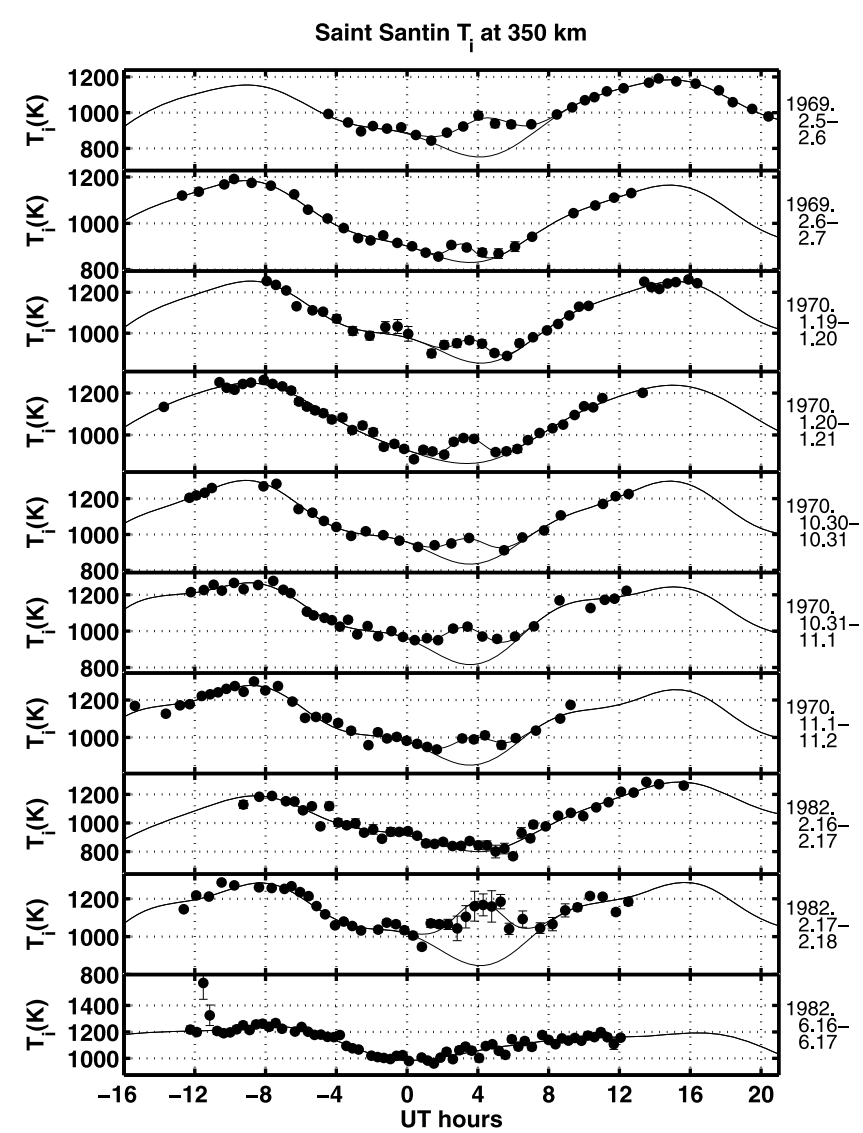

Figure 8. Observations on selected days. 
Saint Santin, Winter, 250km

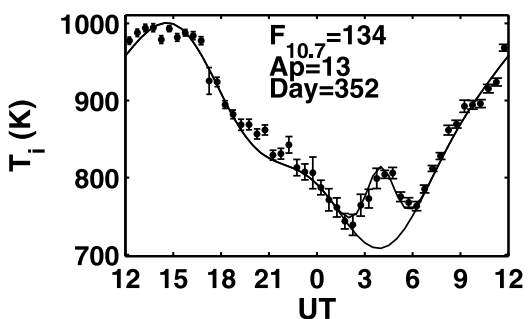

Saint Santin, Winter, 300km

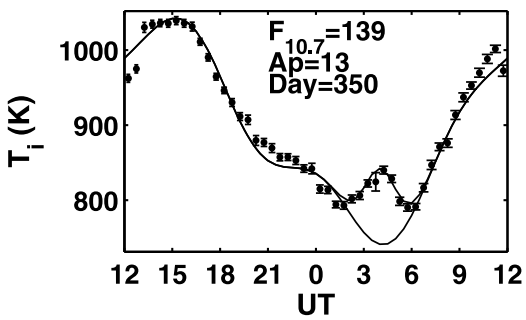

Saint Santin, Winter, 350km

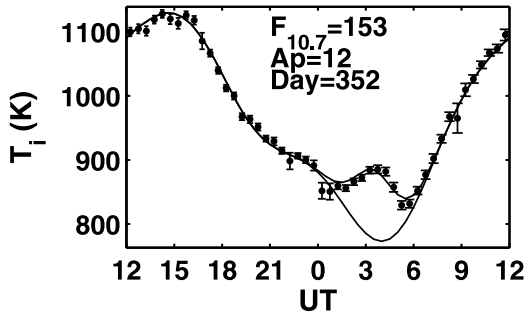

Saint Santin, Winter, 450km

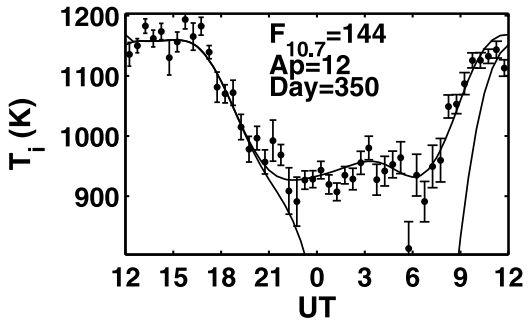

Saint Santin, Winter, 275km

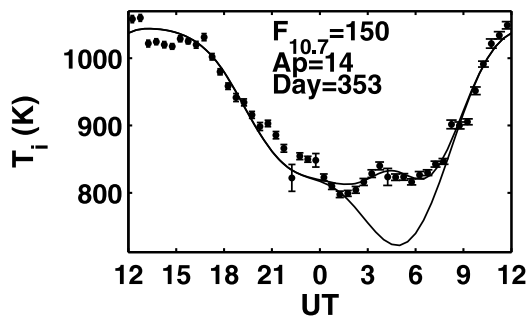

Saint Santin, Winter, 325km

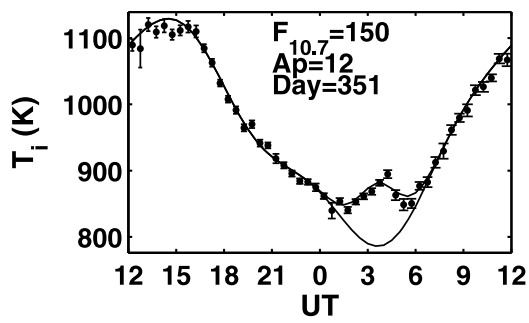

Saint Santin, Winter, 400km

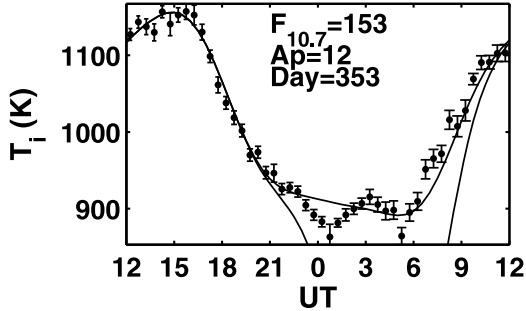

Saint Santin, Winter, 500km

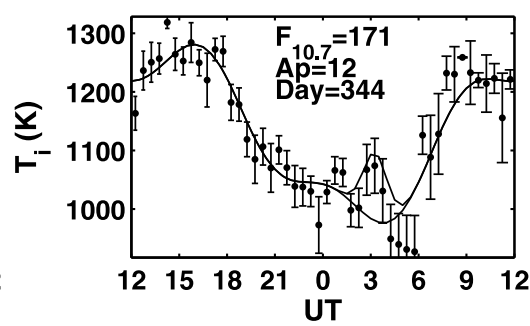

Figure 9. Saint Santin winter enhancement at eight altitudes.

make the conservative decision here just to state that we see an enhancement peak at all observable altitudes in winter above Saint Santin and to base subsequent quantitative conclusions on the fits for altitudes $250-350 \mathrm{~km}$ only.

[15] We have two measures each of enhancement amplitude, center hour, and hour width, the $p_{32}, p_{33}$, and $p_{34}$ parameters of the gaussian, and the corresponding values determined from the peak-and-valley computations. We also have an estimate of the time at which the background atmosphere would have reached its nighttime minimum temperature if the enhancement had not been present. This minimum comes from the lower solid curve shown in Figures 7-9. We have already stated our reservation about the depth of the minimum that this curve may predict. Nevertheless it provides the only estimate we have of the time of occurrence of this minimum in the "background" atmosphere, and we include it below in our tabulated results as it becomes an item of interest in our subsequent speculations on the cause of the enhancement.
[16] Table 1 lists the results obtained for the enhancement in the fitting process.

[17] What does this table show? First, we would say that, with the exception of the day of the seasonal peak, no meaningful patterns of behavior with height are evident. We would highlight the following characteristics of the enhancement:

[18] 1. An amplitude of about $40 \mathrm{~K}$ at winter solstice, based on the conservative peak-to-valley computation. A value closer to the gaussian amplitude of about $110 \mathrm{~K}$ may be more realistic.

[19] 2. A peak hour near 4 UT. Also, a background atmosphere temperature minimum near 4 UT.

[20] 3. A duration of about 4 hours, based on the peakand-valley computations

[21] 4. A seasonal peak that varies smoothly from late November at $350 \mathrm{~km}$ altitude to early January at $250 \mathrm{~km}$ altitude. We can conceive of no process that would cause such a shift and wonder if five data points warrants such a conclusion. 
Table 1. Characteristics of the Nighttime Temperature Maximum

\begin{tabular}{|c|c|c|c|c|c|}
\hline Feature & $250 \mathrm{~km}$ & $275 \mathrm{~km}$ & $300 \mathrm{~km}$ & $325 \mathrm{~km}$ & $350 \mathrm{~km}$ \\
\hline Amplitude $\left(p_{32}, \mathrm{~K}\right)$ & $114 \pm 13$ & $111 \pm 10$ & $101 \pm 8$ & $98 \pm 11$ & $117 \pm 11$ \\
\hline Amplitude (peak-to-valley, K) & 72 & 20 & 48 & 31 & 40 \\
\hline Peak hour $\left(p_{33}\right.$, hours $)$ & $3.99 \pm 0.10$ & $4.70 \pm 0.13$ & $4.05 \pm 0.07$ & $3.68 \pm 0.11$ & $3.56 \pm 0.09$ \\
\hline Peak hour (peak-to-valley, hours) & 4.04 & 4.47 & 4.01 & 3.77 & 3.40 \\
\hline Background minimum hour (hours) & 3.61 & 4.87 & 4.21 & 3.53 & 3.86 \\
\hline Hour width $\left(2 \times p_{34}\right.$, hours $)$ & $1.83 \pm 0.24$ & $3.32 \pm 0.23$ & $2.04 \pm 0.18$ & $2.62 \pm 0.24$ & $2.60 \pm 0.21$ \\
\hline Hour width (peak-to-valley, hours) & 3.87 & 4.88 & 3.81 & 4.19 & 4.35 \\
\hline Peak day number $\left(p_{35}\right)$ & $6 \pm 6$ & $-10 \pm 3$ & $-15 \pm 4$ & $-28 \pm 5$ & $-32 \pm 4$ \\
\hline Day width $\left(2 \times p_{36}\right.$, days $)$ & $97 \pm 13$ & $78 \pm 7$ & $95 \pm 8$ & $102 \pm 8$ & $99 \pm 7$ \\
\hline
\end{tabular}

[22] 5. A seasonal width of about 100 days, about a quarteryear season.

\section{Speculation of the Cause of the Nighttime Temperature Maximum}

[23] We first consider the possibility that the winter nighttime temperature enhancement seen in the $\mathrm{F}$ region over $45^{\circ} \mathrm{N}$ may represent heating resulting from the convergence of global winds to the global pressure minimum. Where is this global pressure minimum? The literature contains several maps showing the global low-temperature point, determined from various in-situ and ground-based techniques and numerical simulations. Maps generated from experimental data include those of COSPAR Working Group IV [1965], Waldteufel and McClure [1969], Waldteufel and Cogger [1971], Jacchia [1971], Hedin et al. [1974], Jacchia [1977], Hedin et al. [1977], and Hedin [1983]. We state here, in order of the references just given, our readings from those maps of the approximate latitude/LT positions of the global minimum for solstice conditions: $25^{\circ} / 4 \mathrm{LT},>45^{\circ} /$ $6-7 \mathrm{LT},>45^{\circ} / 6 \mathrm{LT}, 30^{\circ} / 3 \mathrm{LT}, 50^{\circ} / 5 \mathrm{LT}, 45-50^{\circ} / 5 \mathrm{LT}, 45^{\circ} /$ 5LT, $50-55^{\circ} / 3-4 \mathrm{LT}$. While there may be substantial differences among these estimates, they serve to show that Saint Santin may well rotate close to that minimum in winter. We may note also that ionospheric density is near its nighttime low at this location and offers reduced constraint to wind flow.

[24] Recall also our estimate from the data-fitting process that the background atmosphere would have seen a temperature minimum, had there not been a winter nighttime enhancement, near the same hour, 4 UT, at which the enhancement maximized. There is nothing in the fitting procedure that would constrain the background minimum and the enhancement maximum to coincide in time. This background minimum must approximately identify the longitude of the nighttime pressure minimum, to which the dayto-night winds tend to converge. So we take this coincidence in timing between the background minimum and the enhancement maximum to indicate that the enhancement heating process does occur near the nighttime pressure minimum. We speculate, then, that Saint Santin rotates closest to the center of the region of nighttime heating at winter solstice and so can observe the heating there.

[25] We now consider whether the observed winter nighttime enhancement may represent an extension of the MTM. The pressure bulge associated with the MTM will tend to drive winds toward regions of low pressure, though the tidal forces which may well create the MTM will modify this simple pressure-gradient picture to some degree. A primary comparison here is with the aforementioned brightness-wave (BW) results of Colerico et al. [2006] in which the ionospheric effects of an MTM were seen to propagate poleward and leave the field of view at $39^{\circ}$ latitude after 3 LT. This observation was a composite of a number of days of observation but forms such a consistent pattern that we consider it to be representative. This brightness wave traversed their field of view from $15^{\circ}$ to $39^{\circ}$ latitude in about $110 \mathrm{~min}$, giving a poleward track velocity of about $400 \mathrm{~m} / \mathrm{s}$. A poleward wind was certainly necessary to push ionization down the fields lines and create the increase in photon emission rate observed, but $400 \mathrm{~m} / \mathrm{s}$ seems excessive. Meriwether et al. [2008] estimated a wind velocity of only $50 \mathrm{~m} / \mathrm{s}$ for the period of observation, so it seems impossible that the brightness-wave track velocity represented a wind velocity. Guided by recent results from the Whole Atmosphere Model (WAM) [Akmaev et al., 2009], we suggest that the region of MTM creation was not isolated near the equator during this period but progressed poleward with time, driving winds before it. The BW track would then identify the track of MTM creation, not a propagation from an equatorial source. In any case, continued propagation would lead close to the $45^{\circ} / 4 \mathrm{LT}$ position of Saint Santin, but the season is different, Colerico et al.'s observations being close to equinox, Saint Santin's enhancement being seen in winter. The question of the location of the global pressure minimum at equinox then arises. The first three-dimensional NCAR TGCM [Dickinson et al., 1981], the one that used MSIS composition, found that minimum to be located on the equator, while the following model [Dickinson et al., 1984], that determined composition self-consistently, found pressure minima located about $30^{\circ}$ off the equator in both hemispheres owing to a tongue of warm air extending along the equator from afternoon into the night. If this latter model should be correct, then there would always be an off-equator pressure minimum for MTM winds to seek, regardless of season.

[26] Another feature of the Saint Santin enhancement is its apparent absence on some days. Observers of MTMs often report the number of nights of occurrence and the number of nights of non-occurrence in a data set, rather than a distribution of MTM amplitudes over all days. The distribution has a large tail of near-zero amplitude, which we take to mean that certain atmospheric conditions strongly damp MTM generation. The Saint Santin observations also seem to have a relatively large number of "no-enhancement" days, though, as we have noted, it is more the rule than the exception that irregular behavior masks clear identification. 
Convergence of global-scale winds should happen consistently day by day, while MTMs often do not develop.

[27] Perhaps these two speculations on the origin of the Saint Santin enhancement may be combined into one, of an "permanent" MTM of variable nightly amplitude generating winds that blow to the global pressure minimum and deposit their energy there, creating a local hot spot under which Saint Santin rotates in winter.

[28] Why do semi-empirical models, like the MSIS series [e.g., Hedin, 1987], not show this nighttime temperature enhancement? Figure 5 shows that our own modeling missed the effect when we included only large-scale diurnal harmonics, with periods of 24,12 , and 8 hours, in fitting the data. The feature stood out clearly when we added a model feature appropriate to the temporal behavior of the feature. Community models use these same three diurnal harmonics and so may also just smooth through the feature. It seems pertinent that Mayr et al. [1979] note that the OGO-6 model, based on data collected above $400 \mathrm{~km}$ altitude, did show an MTM-like feature, but when the data base was expanded to use additional satellite data from lower altitudes, forming the MSIS model, the feature was lost. It is necessary to adopt correct functional forms in such models if features of those forms are to be modeled effectively. If the MSIS model can miss the MTM, it may miss the Saint Santin enhancement. Evidence of the enhancement, should it exist, should be available in the data bases from which the MSIS models were made.

[29] Why do numerical simulations not show this nighttime temperature enhancement? Until recently we could have noted that numerical simulations do not show the MTM either, but the new Whole Atmosphere Model (WAM) of Akmaev et al. [2009] has succeeded in producing this feature, not as result of air masses colliding at the equator [e.g., Meriwether et al., 2008], but from the preferential vertical propagation of the nighttime cycle of the terdiurnal tide. Akmaev et al. [2009, Figure 5] address the December solstice case of particular interest for the Saint Santin observations. That figure shows the MTM to have a fixed local-time/latitude structure, extending to midlatitudes at later local times, not because of propagation to higher latitude but simply as a reflection of the latitudinal structure of the terdiurnal mode. That figure also shows the amplitude of the MTM temperature enhancement to increase poleward from the equator, more strongly in winter than summer, maximizing at a hot spot near $40^{\circ} \mathrm{N}$ and $2 \mathrm{LT}$, disappearing soon beyond this location. It also shows a global temperature minimum to form near $40^{\circ}$ latitude and $5 \mathrm{LT}$, but no local maximum to be superposed on it. WAM would come closer to reproducing the Saint Santin winter enhancement observations if its terdiurnal pattern were delayed two hours. If so shifted, then WAM's MTM hot spot would nearly coincide in time and space with the Saint Santin enhancement, and the MTM extension from the equator would terminate right there. In any case WAM portends a breakthrough in the study of the MTM, and gives possible interpretation of the Saint Santin winter nighttime temperature enhancement as a feature of the latitudinal extension of that MTM.

[30] Akmaev et al. [2009] noted that a key feature of their MTM generation was the vertical propagation of the threepeaked terdiurnal structure, with two of the three structures being suppressed by enhanced dissipation during daytime and only the nighttime structure surviving with substantial magnitude. We wish to note from our Table 1 that the peakto-valley width of our enhancement is about four hours, which would match the duration of the positive half of an eight-hour wave.

[31] What should other sites see if they were to look for a nighttime temperature enhancement like the one seen above Saint Santin? If the enhancement should be associated with the global pressure minimum, they should see it in winter, not summer, near $4 \mathrm{LT}$, if they are in the latitudinal vicinity of that minimum. If they see the enhancement at the equinoxes, they may well be seeing the off-equator pressure minima forecast by the model of Dickinson et al. [1984] for equinox. On the other hand, if the MTM should be the long latitudinal structure from equator to midlatitudes portrayed by WAM, a low-latitude or midlatitude site would observe a nighttime enhancement every night as the site rotated under the structure. There should certainly be ground-based or optical data bases available to check these predictions.

\section{Summary}

[32] The Saint Santin incoherent scatter radar data base shows a permanent local maximum in nighttime ion temperature at $45^{\circ}$ latitude that occurs in winter only. Its amplitude can exceed $100 \mathrm{~K}$ and averages $40 \mathrm{~K}$ on the basis of a conservative peak-to-valley computation. It peaks near $4 \mathrm{LT}$ and has a duration of about 4 hours. We give two possible explanations for this feature, (1) that it represents heating caused by the convergence of global winds at the global nighttime pressure minimum, under which Saint Santin would rotate in winter, and (2) that it is a high-latitude extension of the MTM. That the Saint Santin enhancement is seen only in winter may argue for former explanation, for the MTM is not restricted to winter. That the MTM has been observed to propagate beyond $39^{\circ}$ latitude at 3 LT may argue that the enhancement is an extension of the MTM. Neither global semi-empirical models based on data nor global numerical simulations based on physics shows this nighttime temperature maximum. The data-based models do not show the better-known MTM either. The more-recent WAM simulations do show a nighttime structure that may represent the Saint Santin enhancement if those structures could be delayed two hours.

[33] Acknowledgments. This work used data accessed from the CEDAR Data Base. The Saint-Santin/Nançay facility was operated with financial support from the Centre National de la Recherche Scientifique. This work was supported through NSF grants ATM-0836452 and AGS0925893. We thank Michael Mendillo for key comments on this study and several prior undergraduate students whose groundwork helped develop our analysis: Monica Ortiz, Cameron Hall, Christopher Miller, Nate Wilkie, and Austin Collins.

[34] Robert Lysak thanks the reviewers for their assistance in evaluating this paper.

\section{References}

Akmaev, R. A., F. Wu, T. J. Fuller-Rowell, and H. Wang (2009), Midnight temperature maximum (MTM) in Whole Atmosphere Model (WAM) simulations, Geophys. Res. Lett., 36, L07108, doi:10.1029/2009GL037759.

Colerico, M. J., M. Mendillo, C. G. Fesen, and J. Meriwether (2006), Comparative investigations of equatorial electrodynamics and low-tomid latitude coupling of the thermosphere-ionosphere system, Ann. Geophys, 24, 503-513.

COSPAR Working Group IV (1965), CIRA 1965: COSPAR International Reference Atmosphere 1965, North-Holland, Amsterdam. 
Dickinson, R. E., E. C. Ridley, and R. G. Roble (1981), A three-dimensional general circulation model of the thermosphere, J. Geophys. Res., 86, 1499-1512.

Dickinson, R. E., E. C. Ridley, and R. G. Roble (1984), Thermospheric general circulation with coupled dynamics and composition, J. Atmos. Sci., 41, 205-291.

Donaldson, J. K., T. J. Wellman, and W. L. Oliver (2010), Long-term change in thermospheric temperature above Saint Santin, J. Geophys. Res., 115, A11305, doi:10.1029/2010JA015346.

Hedin, A. E. (1983), A revised thermospheric model based on mass spectrometer and incoherent scatter data: MSIS-83, J. Geophys. Res., 88 $10,170-10,188$

Hedin, A. E. (1987), MSIS-86 thermospheric model, J. Geophys. Res., 92, 4649-4662.

Hedin, A. E., H. G. Mayr, C. A. Reber, N. W. Spencer, and G. R. Carignan (1974), Empirical model of global thermospheric temperature and composition based on data from the OGO 6 quadrupole mass spectrometer, J. Geophys. Res., 79, 215-225.

Hedin, A. E., et al. (1977), A global thermospheric model based on mass spectrometer and incoherent scatter data MSIS: $1 . \mathrm{N}_{2}$ density and temperature, J. Geophys. Res., 82, 2139-2147.

Jacchia, L. G. (1971), Revised static models of the thermosphere and exosphere with empirical temperature profiles, Spec. Rep., 332, Smithsonian Astrophys. Obs., Cambridge, Mass.
Jacchia, L. G. (1977), Thermospheric temperature, density, and composition: New models, Spec. Rep., 375, Smithsonian Astrophys. Obs., Cambridge, Mass.

King, J. W., and H. Kohl (1965), Upper atmospheric winds and ionospheric drifts caused by neutral air pressure gradients, Nature, 206, 699-701.

Mayr, H. G., I. Harris, N. W. Spencer, A. E. Hedin, L. E. Wharton, H. S Porter, J. C. G. Walker, and H. C. Carlson Jr. (1979), Tides and the midnight temperature anomaly in the thermosphere, Geophys. Res. Lett., 6, $447-450$.

Meriwether, J., M. Faivre, C. Fesen, P. Sherwood, and O. Veliz (2008), New results on equatorial winds and the midnight temperature maximum, Ann. Geophys., 26, 447-466.

Spencer, N. W., G. R. Carignan, H. G. Mayr, H. B. Niemann, R. F. Theis, and L. E. Wharton (1979), The midnight temperature naximum in the Earth's equatorial thermosphere, Geophys. Res. Lett., 6, 444-446.

Waldteufel, P., and L. Cogger (1971), Measurements of neutral temperature at Arecibo, J. Geophys. Res., 76, 5322-5336.

Waldteufel, P., and J. P. McClure (1969), Preliminary comparisons of middle and low latitude Thomson scatter data, Ann. Geophys., 25, 785-793.

Walsh, P. L., and W. L. Oliver (2011), Is thermospheric long-term cooling due to $\mathrm{CO}_{2}$ or $\mathrm{O}_{3}$ ?, Ann. Geophys., 29, 1779-1782. 